\title{
Advanced exponential sliding mode control for microgrid at autonomous and grid-connected modes
}

\author{
A. Elnady ${ }^{1}$, Mohammad AlShabi ${ }^{2}$ \\ ${ }^{1}$ Department of Electrical and Electronics Engineering, University of Sharjah, Sharjah, UAE \\ ${ }^{1}$ Department of Electrical and Computer Engineering, (adjunct), Royal Military College, Ontario, Canada \\ ${ }^{2}$ Department of Mechanical and Nuclear Engineering, University of Sharjah, Sharjah, UAE
}

\begin{tabular}{l} 
Article Info \\
\hline Article history: \\
Received Mar 20, 2020 \\
Revised May 25, 2020 \\
Accepted Jul 17, 2020 \\
\hline Keywords: \\
Advanced exponential SMC \\
Balanced and unbalanced loads \\
Microgrid \\
Multilevel inverter \\
Parallel inverters
\end{tabular}

\begin{abstract}
This paper introduces a novel control scheme for the operation of multilevel inverters forming a microgrid. The core of the suggested control scheme is an advanced (power-rate) exponential sliding mode controller. This developed controller is robust toward any variation of the system's parameters and loads in addition to its fast and accurate performance. The presented control scheme provides advantageous characteristics to the microgrid operation in an autonomous mode (microgrid mode) and grid-connected mode. In the microgrid mode, the voltages and frequency are stable at any variable balanced and unbalanced load. In the grid-connected mode, an effective procedure for connecting the microgrid to the main grid is proposed to guarantee a seamless and fast transition to the grid-connected mode. The performance of the presented control scheme along with its proposed controller is validated by comparing its results to another linear and non-linear controllers for the same microgrid loading conditions.
\end{abstract}

This is an open access article under the CC BY-SA license.

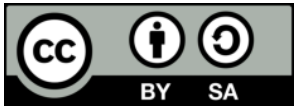

\section{Corresponding Author:}

Mohammad AlShabi,

Department of Mechanical and Nuclear Engineering,

University of Sharjah, Sharjah, UAE.

Email: malshabi@sharjah.ac.ae

\section{INTRODUCTION}

This section covers the background and state-of-art for the control schemes used to operate the microgrid. This section also presents the pitfalls associated with existing schemes and finally it sheds light on the proposed control scheme for the microgrid.

- Background

The microgrid becomes a new promising trend at medium and low voltage levels because it has several merits compared to the traditional central power grid [1]. The microgrid encompasses a group of loads with some distributed generators such as inverters and generators. The inverters are fed by distributed energy resources (DER), while the generators are driven by micro-turbines, wind-turbines, and combustion engines. The microgrid can generally be operated in an autonomous mode (microgrid mode) or a grid-connected mode. Therefore, it has the capability to supply and/or absorb power from the distribution system (power grid) and the distributed generation systems (DGS).

Several review/survey publications have tackled different concepts such as the operation of parallel inverters [2,3], and modeling of microgrids [4, 5]. The microgrid structure and control techniques have been investigated in $[6,7]$ including current control, voltage control, and droop control with some protection issues in microgrids. In $[8,9]$, the control schemes of microgrid are divided into two main categories: Control schemes with communications and without communications. In [8], more details are given for the structure 
of each control scheme within the two preceding categories. Another classification of the control scheme is given as centralized, decentralized, and distributed schemes [10]. The review of power sharing control techniques, (in terms of the communication-based schemes and droop control schemes), is portrayed in [11] with emphasis on the drawbacks of the droop control and how these drawbacks can be mitigated. In [12, 13], a comprehensive review has been conducted on the different controllers that are employed in the primary control loop inside the hierarchical structure of the distributed generation systems and microgrids. Different droop control schemes have been reported in $[14,15]$, where the pitfalls of the droop control are highlighted in [14], the remedy of these pitfalls is discussed in [15], and some detailed control block diagrams of different droop schemes are illustrated in [16]. An advanced classification to what has been published in [10] is also reported in [17-19] in terms of the employed control schemes that are classified as central approaches and decentral approaches. In addition to the aforementioned classification, comparative analysis for many reported control schemes for microgrids in an autonomous mode is documented in [17].

Any developed control scheme depends mainly on its controllers, which are employed to operate their scheme. Several controllers are developed and used in the most inner loop to track the injected current of parallel inverters. The PI controller in the rotating frame and the proportional-resonant (PR) controller in the stationary frame are used to enhance the tracking performance [20,21]. Sliding mode control (SMC) is also adopted to control the current and voltage [22], where the control law of the SMC is a function of the current and voltage errors. In [23], the SMC is also applied on parallel inverters so as to merge the droop control with the voltage to stabilize the voltage and frequency; and consequently, control the injected current. Deadbeat control (pole placement) is widely used for the discrete current control [24, 25], but it is not robust for system uncertainties (unlike the SMC). Its performance is verified for only one inverter [24] and for three inverters [25]. A weighting current controller is adopted in case the ratings of inverters are different [26]. This controller is similar to the conventional current distributed controller, but the only difference is that the current reference of each current loop for each inverter is different from others to match the rating of each inverter. In order to achieve accurate and fast current control, one-cycle control is proposed for parallel inverters, in which the current control is achieved by repeating the control law every cycle [27].

- $\quad$ Problem under study

The problem under study is the development of a centralized control scheme for parallel inverters that is able to operate the microgrid at different modes of operation. The traditional hierarchical structure of droop schemes is thoroughly investigated in [17, 18]. The conventional droop control presents several drawbacks such as cold start of the microgrid [15], frequency and voltage deviation [17], different X/R ratio of the distribution feeder [18], different feeder impedance [7], and harmonic current distribution [11, 28]. The proposed control scheme belongs to the centralized category. This centralized category encompasses the communication-based scheme, which has been employed to control the injected currents of all parallel inverters. For instance, the master-slave scheme along with its derivatives has been presented to coordinate between the voltage controlled and current controlled parallel inverters [29]. This scheme achieves excellent power sharing, yet it suffers from the high overshoot in the current due to any transient in the microgrid. Another example of a centralized control is the circular chain control (3C), which has an inner current loop and an outer voltage loop (usually controlled by PI controllers) such that the successive inverter tracks the previous inverter with an inner current loop to achieve equal current distribution [30].

Proposed solution

In this paper, the novelty is articulated for a centralized current control scheme of parallel inverters for the microgrid operation such that this proposed centralized control scheme depends on a developed cascaded/parallel loop structure. This proposed scheme is based on a robust controller, which is the advanced (power-rate) exponential sliding mode controller. This structure (cascaded/parallel loops) is employed in an autonomous mode, (voltage/current control mode), and in a grid-connected mode (power control mode). This scheme does not entail any intercommunication among the inverters. In addition, any inverter can be taken out or re-connected without disturbing the operation of the microgrid. Furthermore, the presented scheme is utilized for any variable balanced or unbalanced load. This paper has five sections; the proposed scheme is explained in the second section. The research method is explained in the third section. The results and discussions are listed in the fourth section, and the conclusion is written in the last section.

\section{PROPOSED SCHEME}

This section shows the proposed control scheme along with the configuration of the microgrid under study.

\subsection{Microgrid configuration}

The system under study is presented in Figure 1, and it shows the connections of the closely-spaced inverters to the point of common coupling (PCC) of loads. The parameters of the system are given in the 
Table 1. The inverters' side of Figure 1 has three dispersed identical inverters, and the output of the control scheme is applied on each inverter at the same time. The objective of the control scheme is to stabilize the voltage along with its frequency at the PCC to match the condition given in the IEEE Standard 1547.4-2011 in addition to equal power/current sharing among the working inverters. Each inverter is a three-phase 5-level diode-clamped inverter [31].

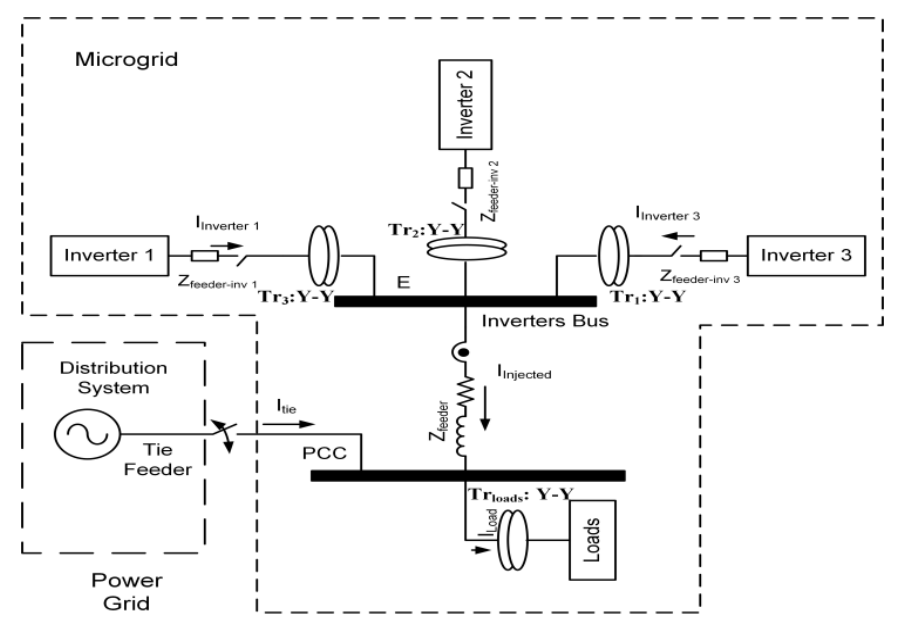

Table 1. Distribution system parameters

\begin{tabular}{cc}
\hline PARAMETER & VALUE \\
\hline Voltage level & $=6.6 \mathrm{kV}$ \\
Microgrid rating/base & $=7.5 \mathrm{MVA}$ \\
Power rating/inverter & $=0.75 \mathrm{MVA}$ \\
Feeder impedance $Z_{f}$ & $=1.2 \Omega+1.5 \mathrm{j} \Omega$ \\
Trans $T_{r 1}, T_{r 2}, T_{r 3}$ & Similar \\
Trans $T_{r 1}$ & $=0.75 \mathrm{MVA}$ \\
Trans $T_{r 1}$ voltage ratio & $1.32 \mathrm{kV}: 6.6 \mathrm{kV}$ \\
Trans $T_{\text {loads }}$ rating & $=2.5 \mathrm{MVA}$ \\
Trans $T_{\text {loads }}$ voltage ratio & $6.6 \mathrm{kV}: 0.4 \mathrm{kV}$ \\
Trans $T_{r 1}, T_{\text {loads }}$ resistance & $=0.0101 \mathrm{pu}$ \\
Trans $T_{r 1}, T_{\text {loads }}$ inductance & $=0.1 p u$ \\
Inverter type & Diode-clamped \\
Number of parallel inverters & five-level inv. \\
& Three \\
\hline
\end{tabular}

Figure 1. Microgrid system under study (star-configuration)

\subsection{Proposed control scheme for microgrid operation}

The proposed control scheme consists of three main loops and the whole scheme is implemented in the $d-q$ rotating frame to gain the benefits and simplicity of working on this rotating frame [2-7, 12-17]. The proposed structure is depicted in Figure 2. The suggested control scheme is split into three major loops: Positive-sequence voltage loop, negative-sequence voltage loop, and power management loop. Each sequence loop has two cascaded loops (primary and secondary) and they are employed for the microgrid mode. The third main loop is designed for the power management control for the grid-connected mode.

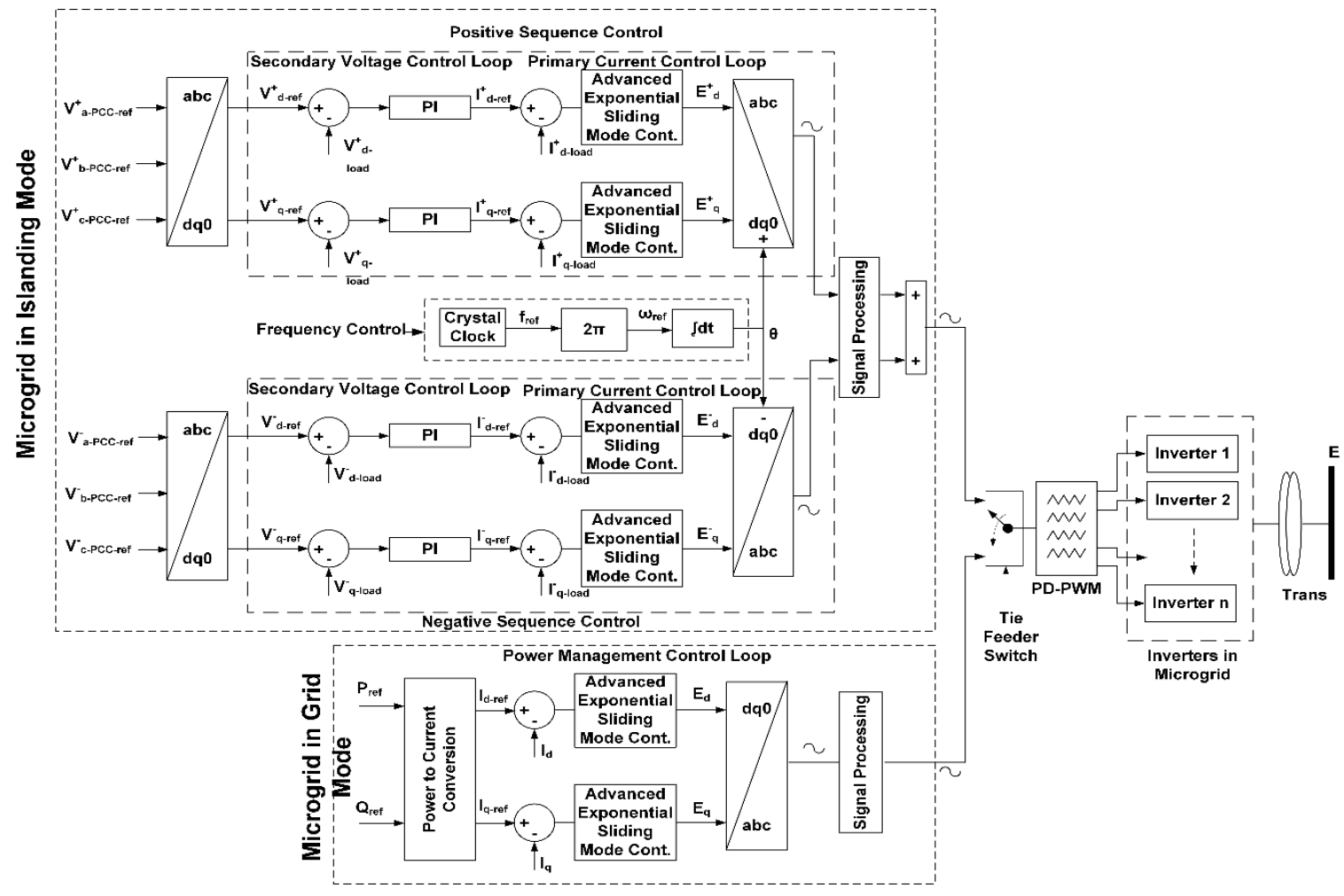

Figure 2. Proposed control scheme for microgrid operation 
In the primary current control loop, the relation between the current reference and the required injected voltage of inverters is not linear due to the existence of the multilevel inverter along with its switching modulation. In addition, the output of the primary current control loop is used to drive the switching modulation of each inverter, which is the phase-disposition pulse with modulation (PD-PWM) [31]; consequently, the control signals of the PD-PWM are applied on each inverter separately (inverters 1,2 and 3) at the same time to operate each inverter independently off others as shown in Figure 2. Therefore, the suggested controller of both primary loop and power loop is the developed advanced (power-rate) exponential sliding mode controller to overcome the nonlinearity of the microgrid and to have a robust performance at any operating condition. Whereas, the secondary voltage control loop controller is a regular PI controller since the load voltage and load current have a linear relation at almost all operating conditions. One major advantage of this centralized current control scheme is that the outputs of all inverters are synchronized because all inverters are working based on the same control signals, which are applied on all inverters at the same time. This synchronization is really useful for the parallel identical inverters because it minimizes the circulating current, and each inverter output is not influenced by different feeder impedances and $\mathrm{X} / \mathrm{R}$ ratio unlike the case of some droop control schemes [7].

The frequency of the generated voltage is determined by an open loop frequency because its frequency is driven by an internal crystal clock or it may also be obtained from the adjacent power grid through a PLL circuit. This frequency does not change with any loading condition (unlike the droop control). In order to tackle the case of unbalanced loads, the proposed scheme of Figure 2 considers both the positive-sequence and negative-sequence control. The control structure of the positive-sequence is similar to the negative-sequence with the exception of the voltage references. The positive-sequence voltage references are $V_{a-P C C-r e f}^{+}=3.81 \angle 0^{0} \mathrm{kV}, \quad V_{b-P C C-r e f}^{+}=3.81 \angle-120^{0} \mathrm{kV}, \quad V_{c-P C C-r e f}^{+}=3.81 \angle 120^{\circ} \mathrm{kV}, \quad$ which are equivalent to the standard voltages for the system under study, and the negative-sequence voltage references are $V_{a-P C C-r e f}^{-}=V_{b-P C C-r e f}^{-}=V_{c-P C C-r e f}^{-}=0 \mathrm{kV}$ so as to eliminate the negative-sequence components.

\section{RESEARCH METHODOLOGY}

This section exhibits the mathematical formulation for the proposed controller and some other controllers.

\subsection{Mathematical formulation of control scheme}

This section demonstrates the formulation and stability analysis of the proposed controller. The secondary control loop that stabilizes the load voltage around $100 \%$ (equivalent to $1 \mathrm{pu}$ ) is designed to have a linear controller because the relation between the load voltage and load current of Figure 1 is linear at the most of operations as given in the $d-q$ frame by,

$$
V_{d-\text { load }}^{+-}=I_{d-\text { load }}^{+-} Z_{\text {loads }}^{+-}, \quad V_{q-\text { load }}^{+-}=I_{q-\text { load }}^{+-} Z_{\text {loads }}^{+-}
$$

where $Z_{\text {loads }}^{+-}$is the equivalent positive- and negative-sequence impedance of loads, which are linear for balanced and unbalanced loads, $V_{d-\text { load }}^{+-}$and $I_{d-\text { load }}^{+-}$are the positive/negative load voltage and current in the $\mathrm{d}$-axis, and $V_{q-\text { load }}^{+-}$and $I_{q-\text { load }}^{+-}$are the positive/negative load voltage and current in q-axis, respectively. The superscript sign (+ or -) is replaced by $j$, where $j$ means either positive- or negative-sequence components for the equation. For simple and efficient dynamic performance of the secondary voltage control loop, a regular PI controller gives satisfactory performance. While, the primary current control loop that governs the injected current is designed to have an advanced (power-rate) exponential SMC. The relation between the inverters' voltage and loads' voltage can be derived with help of Figure 1 for the positive- and negative-sequence voltage equations in the $d-q$ frame as,

$E_{i}^{j}=V_{i-l o a d s}^{j}+R I_{i-\text { loads }}^{j}-\omega L I_{i-\text { loads }}^{j}+L \frac{d I_{i-l o a d s}^{j}}{d t}, i$ is $d$ or q and $j$ is + or - components

$\frac{d}{d t}\left[\begin{array}{l}I_{d \text {-loads }}^{j} \\ I_{q \text {-loads }}^{j}\end{array}\right]=\frac{-1}{L}\left[\begin{array}{cc}R & -\omega L \\ \omega L & R\end{array}\right]\left[\begin{array}{c}I_{d \text {-loads }}^{j} \\ I_{q \text {-loads }}^{j}\end{array}\right]+\frac{1}{L}\left[\begin{array}{ll}1 & 0 \\ 0 & 1\end{array}\right]\left[\begin{array}{c}E_{d}^{j} \\ E_{q}^{j}\end{array}\right]-\frac{1}{L}\left[\begin{array}{ll}1 & 0 \\ 0 & 1\end{array}\right]\left[\begin{array}{c}V_{d-\text { loads }}^{j} \\ V_{q-\text { loads }}^{j}\end{array}\right]$,

$\rightarrow \dot{x}^{j}=A^{j} x^{j}+B^{j} u^{j}+F^{j} d^{j}$

The inputs to the microgrid $\left(u^{-}, u^{+}\right)$represent the required injected voltage by the inverters $\left(E_{d}^{+}, E_{q}^{+}, E_{d}^{-}, E_{q}^{-}\right)$, and they are converted from the $d-q$ rotating frame to the $a-b-c$ natural frame using the inverse Park transformation with a constant frequency obtained from the frequency loop as illustrated in Figure 2. 
These resultant voltages in the $a-b-c$ natural frame are divided by equivalent $V_{D C}$ so as to generate the control signals for operating the switching modulation (PD-PWM), which perfectly fits the operation of the utilized 5-level diode clamped inverters. To relate the input of the primary control loop $\left(I_{\text {ref }}\right)$ to its output $(E)$, an effective control law of the sliding mode control is developed along with its terms through four propositions associated with their proof.

\section{Proposition 1:}

The proposed control law of the suggested controller is given by the following formula as,

$u^{j}=-\left(\lambda_{1}^{j} B^{j}\right)^{-1}\left(A^{j} x^{j}+F^{j} d^{j}-\lambda_{2}^{j} e^{j}\right)-k^{j}\left|s^{j}\right|^{\mu^{j}} \operatorname{sat}\left(s^{j}\right) /\left(\delta_{0}^{j}+\left(1-\delta_{0}^{j}\right) e^{-\alpha^{j}\left|s^{j}\right|^{\rho^{j}}}\right)$.

where the matrices $\left(A^{j}, B^{j}, F^{j}\right)$ are obtained from (3) based on the system's parameters of Table 1. $\mu^{j}$ is a positive constant less than one. The parameters $\alpha^{j}, \rho^{j,} \delta_{0}^{j}, \lambda_{1}^{j}, \lambda_{2}^{j}$ and $k^{j}$ are strictly positive and $\delta_{0}^{j}<1$.

\section{Proof of Proposition 1:}

The proposed control law consists of two inputs (terms) as follows:

$u^{j}=u_{e q}^{j}+u_{d i s}^{j}$

where $u_{d i s}^{j}$ is the discrete input (discrete term) of the control law that transfers the system's states from a certain sliding manifold (surface) to another, while $u_{e q}^{j}$ is the continuous or equivalent input (continuous term) of the control law that keeps the system's states on a certain sliding manifold. The sliding manifold in this work is defined by an integral form as,

$s^{j}=\left(\lambda_{1}^{j} e^{j}+\lambda_{2}^{j} \int e^{j} d t\right)^{n-1}$

where $n$ is the order of the system and it is equal to two in this system. $\lambda_{1}$ and $\lambda_{2}$ are positive constants, and $e$ is the error and it is defined as,

$e^{j}=I_{d q-r e f}^{j}-I_{d q-l o a d}^{j}$

The rest of the proof will be divided to three main parts: The first part is allocated for the continuous input $u_{e q}^{j}$, the second part is designated for the conventional discrete input $u_{d i s}^{j}$, (conventional version of exponential SMC [32]), and the third part is given for the proposed discrete input $u_{d i s}^{j}$, (proposed version of the exponential SMC).

Part 1: $u_{e q}$ (the continuous input of the proposed control law in (5))

Proposition 2:

The continuous control law of (5), $u_{e q}^{j}$, is given by the following formula as,

$u_{e q}^{j}=-\left(\lambda_{1}^{j} B^{j}\right)^{-1}\left(A^{j} x^{j}+F^{j} d^{j}-\lambda_{2}^{j} e^{j}\right)$

\section{Proof of Proposition 2:}

The first term of (5), $u_{e q}^{j}$, is designed to keep the system's trajectory on a certain manifold, which is, in this work, defined by (6). The system is asymptotically stable if and only if the Lyapunov function $V\left(s^{j}\right)$ is positive and its derivative is negative as follows:

$V\left(s^{j}\right)=0.5 s^{j^{T}} s^{j}>0 \rightarrow \dot{V}\left(s^{j}\right)=\left(d V\left(s^{j}\right) / d s^{j}\right)\left(d s^{j} / d t\right)=s^{j^{T}} \dot{s}^{j} \leq 0$

To maintain the system's states on the sliding manifold, the derivative of that manifold should be zero. For tracking problems like the case of this paper $\dot{V}\left(s^{j}\right)=0 \rightarrow \dot{s}^{j}=0$, which leads to

$$
\begin{aligned}
\dot{s}^{j}=\lambda_{1}^{j} \dot{e}^{j}+\lambda_{2}^{j} e^{j} & =0 \rightarrow \lambda_{1}^{j}\left(\dot{I}_{d q-r e f}^{j}-\dot{I}_{d q-\text { load }}^{j}\right)+\lambda_{2}^{j} e^{j}=-\lambda_{1}^{j}\left(A^{j} x^{j}+B^{j} u_{e q}^{j}+F^{j} d^{j}\right)+\lambda_{2}^{j} e^{j}=0 \\
& \rightarrow u_{e q}^{j}=-\left(\lambda_{1}^{j} B^{j}\right)^{-1}\left(A^{j} x^{j}+F^{j} d^{j}-\lambda_{2}^{j} e^{j}\right)
\end{aligned}
$$


Finally, the continuous input of the proposed control law, (10), is stable when the system trajectory is on the sliding manifold because it is derived through Lyapunov stability procedure.

Part 2: $u_{\text {dis }}$ (the discrete input, conventional exponential SMC, of the control law [32])

Proposition 3:

The discrete input of the control law in (5), $u_{d i s}^{j}$, is defined by an exponential form given in [32] as,

$u_{d i s}^{j}=-k^{j} \operatorname{sign}\left(s^{j}\right) /\left(\delta_{0}^{j}+\left(1-\delta_{0}^{j}\right) e^{-\alpha^{j}\left|s^{j}\right|^{\rho^{j}}}\right)$

where $\operatorname{sign}(d)$ is defined as 1 if $d>0$ and -1 if $d<0 . s$ is the sliding surface and is defined as,

$s^{j}=\left(\lambda^{j} e^{j}+\frac{d}{d t} e^{j}\right)$

This discrete input in (11) ranges from almost $-k^{j} / \delta_{0}^{j}$ for large $s^{j}$ to almost $-k^{j}$ for small $s^{j}$. Thus, this discrete input can reduce the reaching time and the chattering compared to the other conventional SMC (power-rate SMC) [32]. It is noteworthy mentioning that several modifications for the exponential SMC have been proposed to fasten its reaching mode by the proper selection of its parameters as in [33, 34]. The discrete input in [32] is also enhanced in [33] by multiplying a power-rate term to the reaching law of (11) and then adding the resultant term to a proportional-rate term. In [34], the same discrete input of (11) is multiplied by $\sqrt{|s|}$ to minimize the chattering along with the same differential definition of $s$, (12), but the improper selection of the controller parameters makes the performance of the conventional power-rate reaching law faster and smoother than the presented reaching law in [34].

Proof of Proposition 3:

The term $u_{\text {dis }}^{j}$ is defined as the exponential SMC. The stability of this discrete term is proven through its reaching time $\left(T_{r}\right)$, which is derived and proved in [32,33], and using

Lemma 1:

The discrete input of the sliding mode control is stable if it reaching time is finite. The proof of this lemma is already detailed in $[32,33]$. It has been found that the reaching time for (11) can be written in the form of (13).

$T_{r}^{j}=\frac{\left(1-\delta_{0}^{j}\right)}{k^{j}}\left(-\left|S^{j}(0)\right|+\int_{0}^{\left|S^{j}(0)\right|} e^{-\alpha^{j}\left|S^{j}\right|^{\rho^{j}}} d S^{j}\right)=\frac{1}{k^{j}}\left(\delta_{0}^{j}\left|S^{j}(0)\right|+\frac{\left(1-\delta_{0}^{j}\right)}{\alpha^{j}}\left[1-e^{-\alpha^{j}\left|S^{j}\right|}\right]\right)$

Lemma 2:

If the reaching time of proposed discrete input is shorter than the reaching time of another stable discrete input, then the proposed discrete input is stable, and it gives a faster performance in its reaching mode. The proof of this lemma is already detailed in [32]. Furthermore, the research work in [32] shows that (13) is less than the reaching time of the conventional power-rate SMC.

Part 3: $u_{d i s}^{j}$ (the proposed discrete input of the control law in (5))

Proposition 4:

The proposed discrete term of the suggested control law of (4-5) is formulated in this research as,

$u_{d i s}^{j}=-k^{j}\left|s^{j}\right|^{\mu^{j}} \operatorname{sat}\left(s^{j}\right) /\left(\delta_{0}^{j}+\left(1-\delta_{0}^{j}\right) e^{-\alpha^{j}\left|s^{j}\right|^{\rho^{j}}}\right)$

where $s^{j}$ is the sliding surface defined in (6). While, the other parameters are similar to those in formula of (11), and $\operatorname{sat}\left(s^{j}\right)$ function is better than the $\operatorname{sign}\left(s^{j}\right)$ function for chattering reduction.

\section{Proof of Proposition 4:}

In this paper, the proposed control law (4-6) has a finite reaching time that is shorter than the reaching time of the stable controller reported in [32]. According to Lemma 1 and Lemma 2, the proposed controller is stable and has a faster performance than the controller presented in [32]. The proof of stability for the suggested discrete control law in (14) along with its derived reaching time is fully detailed in [32,33]. For the sake of extra clarification, the key equations of this research can be summarized as follows:

The reaching time of the proposed discrete input is calculated in this research as, 
$T_{r}^{j} \leq\left\{\begin{array}{cc}\frac{2}{k^{j}}\left[\Gamma\left(\frac{1-\mu^{j}}{\rho^{j}}\right)\right]^{\frac{1-\rho^{j}}{1-\mu^{j}}}\left(1-\delta_{0}^{j}\right)^{\frac{1-\rho^{j}}{1-\mu^{j}}}\left[\frac{1}{\rho^{j}}\right]^{\frac{1-\rho^{j}}{1-\mu^{j}}}\left|S^{j}(0)\right|^{\rho^{j}-\mu^{j}}\left(1-\mu^{j}\right)^{\frac{-\rho^{j}+\mu^{j}}{1-\mu^{j}}} \delta_{0}^{\frac{\rho^{j}-\mu^{j}}{1-\mu^{j}}} & \rho^{j} \neq 1 \\ \frac{2}{k^{j}} \frac{\left|S^{j}(0)\right|^{1-\mu^{j}} \delta_{0}^{j}}{\left(1-\mu^{j}\right)} & \rho^{j}=1\end{array}\right\}$

The reaching time of the proposed controller is compared to what was presented in [32], which was:

$T_{r}^{\prime \prime j}=\frac{2}{k^{j}}\left|S^{j}(0)\right| \delta_{0}^{j}$

Subtracting (16) from (15) and Choosing $\left|S^{j}(0)\right|$ to be as in (17) give (18).

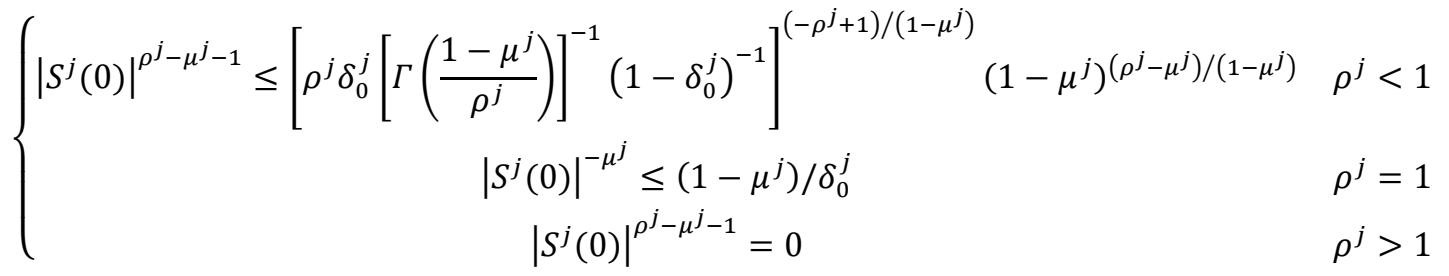

$T_{r}^{j}-T_{r}^{\prime \prime} \leq 0$ for any $\rho^{j}$

The inequality of (18) firmly proves that $T_{r}^{j} \leq T_{r}^{\prime \prime}$, which verifies that the proposed controller has a shorter reaching time than that of the controller presented in [32], and it is also stable during its reaching mode.

\subsection{Comparing the proposed controller to another efficient SMC controller}

To justify the meritorious performance of the proposed control law in (4-6) with its two terms in $(8,14)$, its performance is compared to another an efficient version of the SMC called power-rated SMC [34]. Therefore, this power-rate SMC has a control law as given in (5-6) with a continuous input term $\left(u_{e q}^{j}\right)$ as defined (8), but its discrete input term has been improved in this research by adding a boundary layer as,

$u_{\text {dis }}^{j}=\left\{\begin{array}{l}-k_{1}^{j}\left|s^{j}\right|^{\alpha^{j}} \rightarrow s^{j}>\beta^{j} \\ -s^{j} / \beta^{j} \rightarrow-\beta<s^{j}<\beta^{j} \\ +k_{2}^{j}\left|s^{j}\right|^{\alpha^{j}} \rightarrow s^{j}<-\beta^{j}\end{array}\right.$

where $k_{1}^{j}$ and $k_{2}^{j}$ are positive constants, and $\beta^{j}$ is the width of the boundary loop. Finally, the control law of (5-6) along with its two terms in $(8,19)$ is aggregated to form the power-rate SMC. The output of the designated controller is used to generate the required injected positive voltages $\left(E_{d}^{+}, E_{q}^{+}\right)$so that the voltage remains $100 \%(1 \mathrm{pu})$ at the PCC. Eventually, these voltages $\left(E_{d}^{+}, E_{q}^{+}\right)$are converted to the $a-b-c$ natural frame using the inverse Park's transformation; and consequently, they are mathematically processed to generate the control signals for the PD-PWM. Table 2 shows the parameters of the power-rate SMC for comparison with the suggested controller.

Table 2. Settings of power-rate SMC

\begin{tabular}{cccc}
\hline \multicolumn{2}{c}{ PARAMETERS IN OF THE PRIMARY CONTROL LOOP } & \multicolumn{2}{c}{ PARAMETERS IN OF THE SECONDARY CONTROL LOOP } \\
\hline d-AXIS-CURRENT & q-AXIS-CURRENT & d-AXIS-CURRENT & q-AXIS-CURRENT \\
\hline$\lambda_{1}=1, \lambda_{2}=100$ & $\lambda_{1}=1, \lambda_{2}=81$ & $K_{q p}=0.282$ & $K_{q p}=0.423$ \\
$k_{1}=k_{2}=0.8$ & $k_{1}=k_{2}=0.8$ & $K_{d i}=1.333$ & $K_{d i}=0.111$ \\
$\alpha=0.5, \beta=20$ & $\alpha=0.5, \beta=20$ & & \\
\hline
\end{tabular}

\subsection{Comparing the proposed controller to PI controller}

The proposed control scheme is also compared to the PI controller-based control scheme. The PI controller cannot be applied to the same control scheme of Figure 2 directly, but the control scheme of 
Figure 2 should be slightly modified based on the formulas given in (2). This modified scheme is depicted in Figure 3, and its controllers' parameters are given in Table 3. The PI -based scheme of Figure 3 shows just the positive-sequence control, $(+\omega$ is replaced by $-\omega$ for the negative-sequence control block diagram).

Table 3. Setting of PI controllers' parameters

\begin{tabular}{cccc}
\hline \multicolumn{4}{c}{ Parameters of PI controllers } \\
\hline d-AXIS FOR V $_{\mathrm{d}}$ & $\mathrm{q}$-AXIS FOR V & d-AXIS FOR I & q-AXIS FOR I \\
\hline$K_{p}=0.055$ & $K_{p}=0.055$ & $K_{p}=6.25$ & $K_{p}=1.5$ \\
$K_{i}=0.333$ & $K_{i}=0.111$ & $K_{i}=50$ & $K_{i}=50$ \\
\hline
\end{tabular}

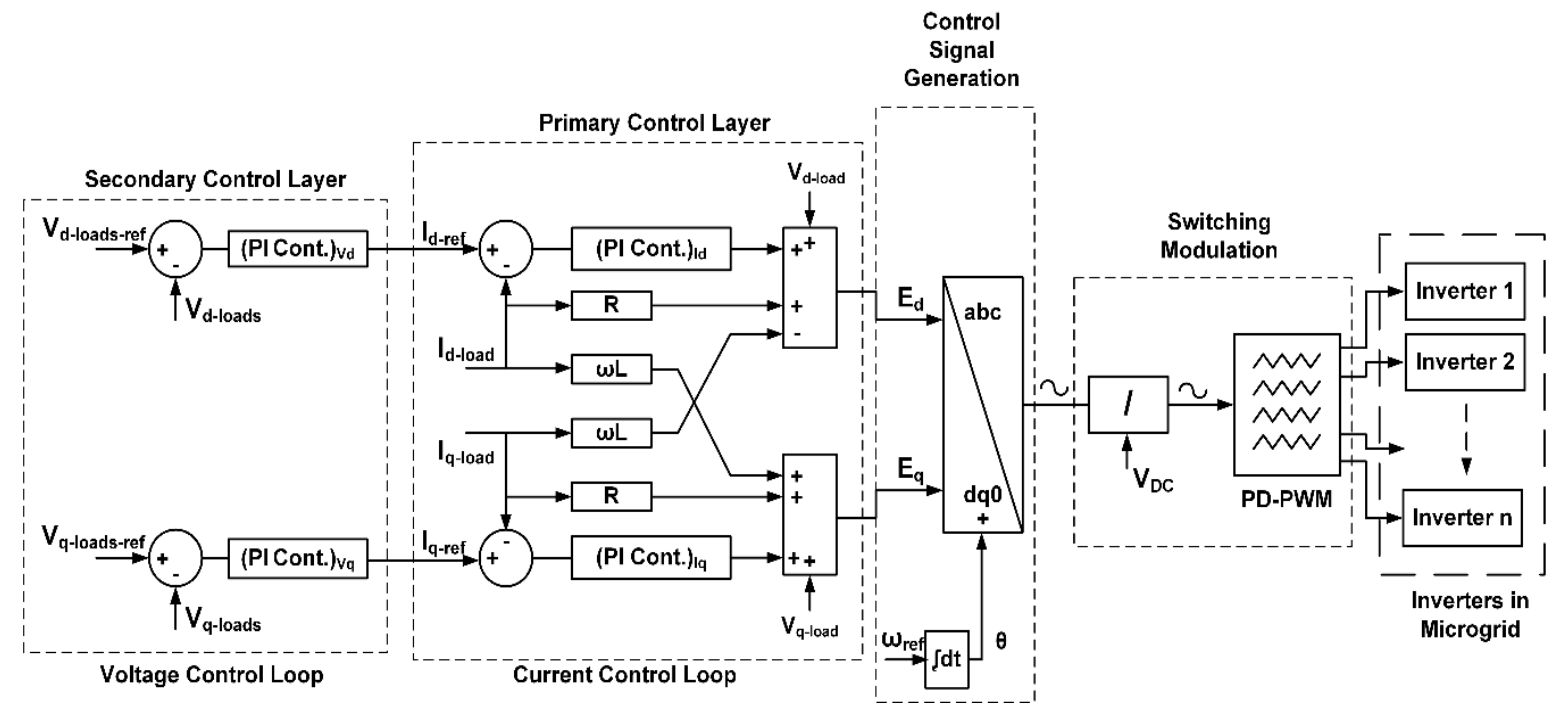

Figure 3. Proposed PI controller-based control scheme for positive-sequence component

\section{RESULTS AND DISCUSSION}

This section shows the performance of the proposed control scheme along with the developed controller for the microgrid operation in different modes.

\subsection{Variable balanced loads in microgrid operation}

This section shows the performance of the developed control scheme for variable balanced loads, where the equivalent load per phase is the parallel combination between $Z_{\text {load } 1}=55+18.84 j$ and $Z_{\text {load } 2}=65+31.4 j$ for time from $\mathrm{t}=0 \mathrm{~s}$ to $\mathrm{t}=4 \mathrm{~s}$. Then, $Z_{\text {load } 2}$ is disconnected starting from time $\mathrm{t}=4 \mathrm{~s}$. This section shows the performance of the proposed controller listed in $(4-6,8,14)$ compared to the conventional power-rate SMC listed in $(5-6,8,19)$ and the PI -based same control scheme of Figure 3.

\subsubsection{Performance of proposed control scheme}

The parameters of the positive-sequence controllers are listed in Table 4. The operation of the microgrid depends on the control block diagram of Figure 2, (just the positive-sequence component loop because the loads are balanced). The output of the primary control loop, which is the required injected voltages $\left(E_{d}, E_{q}\right)$ in the $d-q$ rotating frame, is shown in Figure 4 (a). The instantaneous percent RMS of the voltage at the PCC is given in Figure 4 (b). The three-phase voltage waveforms at the PCC at time $\mathrm{t}=7.9 \mathrm{~s}$ are shown in Figure 5 (a). The main advantage of the using the multilevel inverter is to minimize the injected harmonics. Then, the voltage total harmonic distortion (THD) is shown in Figure 5 (b). Another objective of the proposed control of Figure 2 is to distribute the load power/current equally among the working inverters. Figure 5 (c) illustrates the total active power consumed by all loads in the microgrid and the injected active power by each inverter, (each curve is around one third of the total power), which proves a smooth and fast transition from one loading condition to another. The proposed controller performance indicates that the maximum settling time is almost $0.5 \mathrm{~s}$ for any change in the balanced loads as depicted in Figure 4 (b). 
Table 4. Settings of proposed controllers for the positive-sequence voltage

\begin{tabular}{cccc}
\hline \multicolumn{2}{c}{ PARAMETERS OF PROPOSED SMC IN CURRENT } & \multicolumn{2}{c}{ PARAMETERS OF PROPOSED SMC IN VOLTAGE } \\
\hline $\mathrm{d}$ - AXIS & $\mathrm{q}$ - AXIS & $\mathrm{d}$ - AXIS & q- AXIS \\
\hline$\lambda_{1}^{+}=1, \lambda_{2}^{+}=100$ & $\lambda_{1}^{+}=1, \lambda_{2}^{+}=81$ & $K_{d p}=0.282$ & $K_{q p}=0.423$ \\
$k^{+}=0.8, \alpha^{+}=0.05$ & $k^{+}=0.8, \alpha^{+}=0.05$ & $K_{d i}=1.333$ & $K_{q i}=0.111$ \\
$\mu^{+}=0.95, \rho^{+}=0.5, \delta_{0}^{+}=0.3$ & $\mu^{+}=0.95, \rho^{+}=0.5, \delta_{0}^{+}=0.5$ & & \\
$\lambda_{1}^{+}=1, \lambda_{2}^{+}=100$ & $\lambda_{1}^{+}=1, \lambda_{2}^{+}=81$ & \\
$k^{+}=0.8, \alpha^{+}=0.05$ & $k^{+}=0.8, \alpha^{+}=0.05$ & & \\
\hline
\end{tabular}

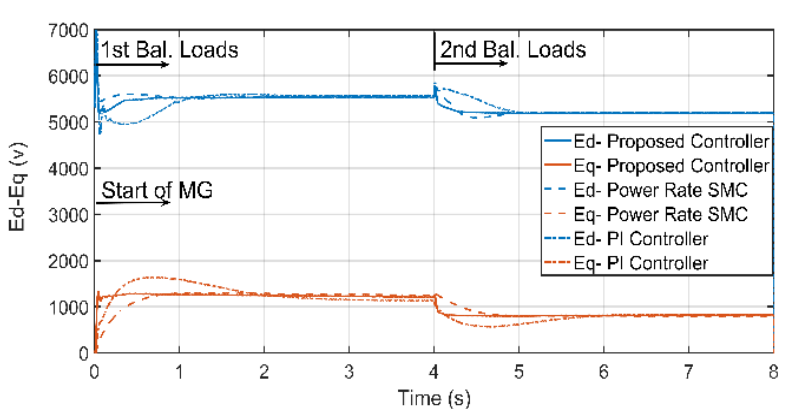

(a)

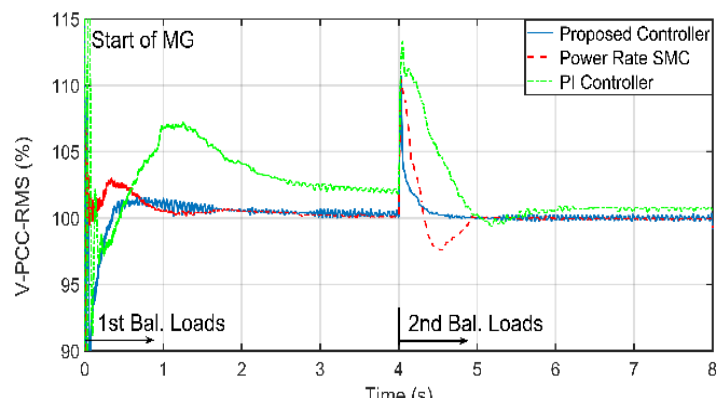

(b)

Figure 4. (a) Outputs of primary current control loop for proposed controller, power-rate SMC and PI controller, (b) Instantaneous percent RMS voltage at PCC for proposed controller, power-rate SMC and PI

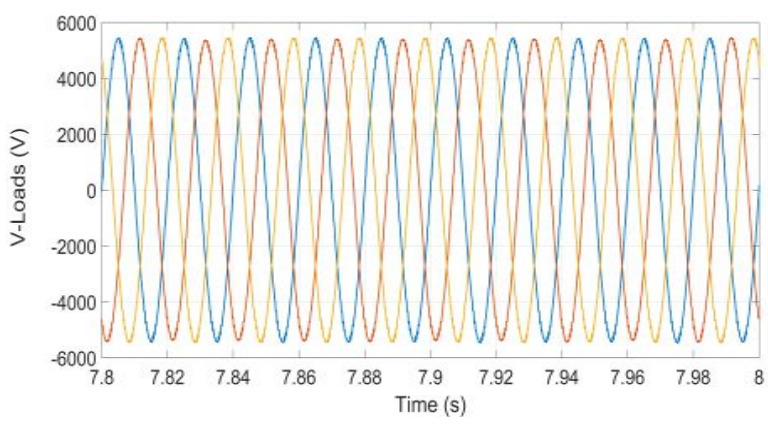

(a)

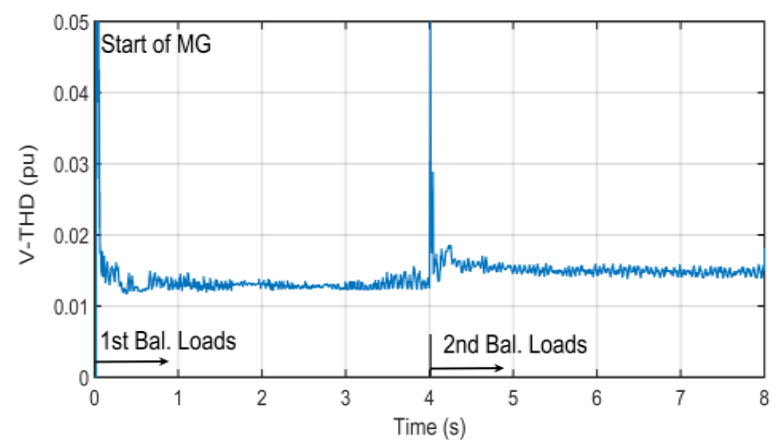

(b)

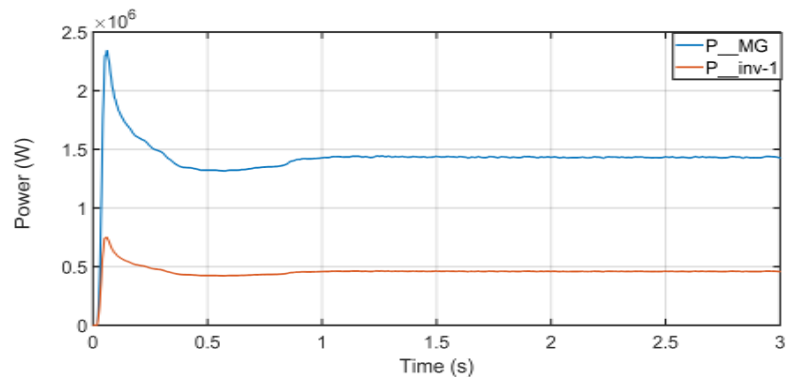

Figure 5. (a) Instantaneous three-phase voltages, (b) THD in percent of voltage at PCC, (c) Power sharing

\subsubsection{Performance of power-rate SMC (nonlinear) and PI controller (linear)}

To justify the meritorious performance of the proposed controller, its performance should be compared to other efficient nonlinear/linear controllers. The suggested candidate for this comparison is the power-rate SMC as defined in $(5-6,8,19)$, which gives better performance than the conventional exponential SMC as proved in [34]. The power-rate SMC controllers replace the suggested advanced exponential sliding mode controller in the control scheme of Figure 2 and the rest of the system/scheme with their parameters are the same.

While the PI controller has its own scheme as depicted in Figure 3 and explained in section 3.3. The output of the primary control loop and the instantaneous percent RMS voltage at the PCC are shown in Figure 4 (a) and Figure 4 (b), respectively. Apparently, the proposed controller outperforms the presented 
power-rate SMC and PI controllers in terms of the transient performance (settling time) and the overall controller performance in the reaching and sliding modes. The performance of PI controller is not guaranteed to give its best performance at different operations.

\subsection{Variable unbalanced loads in microgrid operation}

This section proves that the proposed scheme fits the operation of the microgrid under balanced and unbalanced loads. Before time $\mathrm{t}=8 \mathrm{~s}$, the balanced load per phase is $Z_{\text {load } 1}=55+18.84 j$, then at time $\mathrm{t}=8 \mathrm{~s}$, three different loads of $Z_{\text {load }-a}=25+6.28 j, Z_{\text {load }-b}=50+31.4 j$, and $Z_{\text {load }-c}=35+15.7 j$ are attached in parallel to the original balanced loads. At time $\mathrm{t}=10 \mathrm{~s}$, three extra different loads of $Z_{\text {load }-a}=30+9.42 j$, $Z_{\text {load }-b}=35+11 j$, and $Z_{\text {load }-c}=45+14.13 j$ are connected to the loads mentioned before. The parameters of the controllers for the negative-sequence voltage are written in Table 5. The impact of the proposed scheme on the mitigation of the unbalanced voltage is reflected on stabilizing the positive-sequence voltage at $100 \%(1 \mathrm{pu})$ and mitigating the negative-sequence voltage to the lowest value. The output of the primary current control loop is given in Figure 6 (a), the three-phase voltage waveforms are portrayed for the $2^{\text {nd }}$ unbalanced loads in Figure 6 (b).

Table 5. Settings of proposed controllers for the negative-sequence voltage

\begin{tabular}{cccc}
\hline \multicolumn{2}{c}{ PARAMETERS OF PROPOSED SMC IN CURRENT } & \multicolumn{2}{c}{ PARAMETERS OF PROPOSED SMC IN VOLTAGE } \\
\hline d- AXIS & q- AXIS & d- AXIS & q- AXIS \\
\hline$\lambda_{1}^{-}=1, \lambda_{2}^{-}=81$ & $\lambda_{1}^{-}=1, \lambda_{2}^{-}=81$ & $K_{d p}=0.282$ & $K_{q p}=0.423$ \\
$k^{-}=0.8, \alpha^{-}=1$ & $k^{-}=0.8, \alpha^{-}=1$ & $K_{d i}=1.333$ & $K_{q i}=0.111$ \\
$\mu^{-}=0.5, \rho^{-}=0.95, \delta_{0}^{-}=0.5$ & $\mu^{-}=0.5, \rho^{-}=0.95, \delta_{0}^{-}=0.5$ & & \\
\hline
\end{tabular}

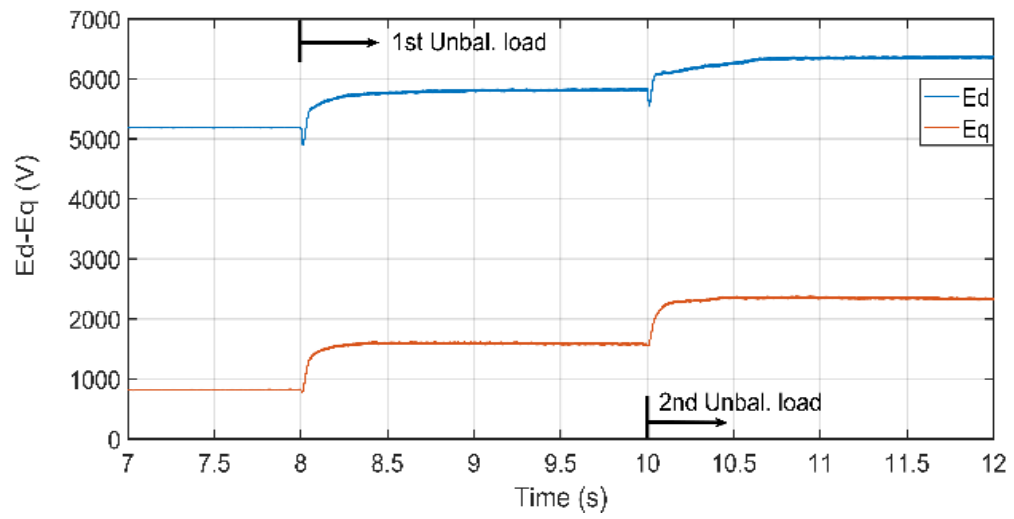

(a)

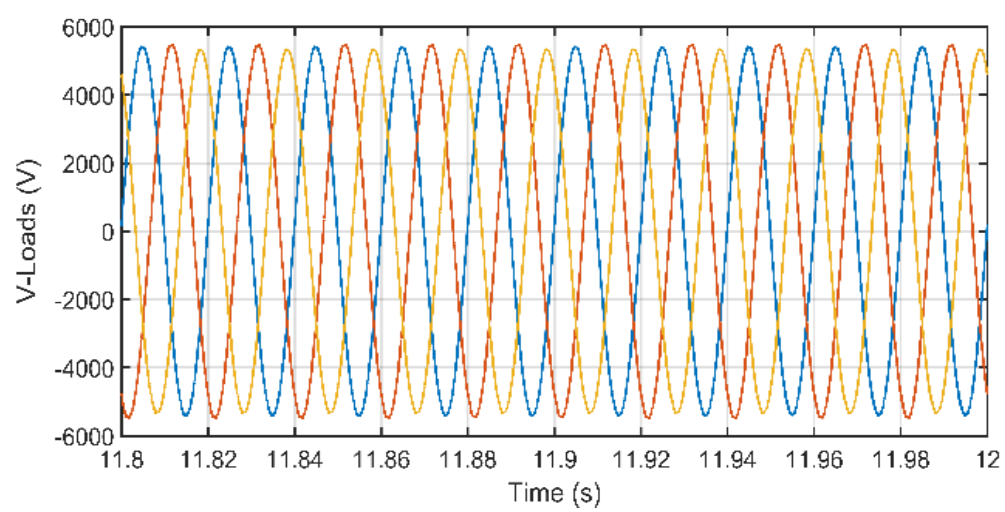

(b)

Figure 6. (a) Output of the primary current control loop at variable unbalanced loads,

(b) Three-phase voltage waveforms at PCC at 2nd unbalanced loads 


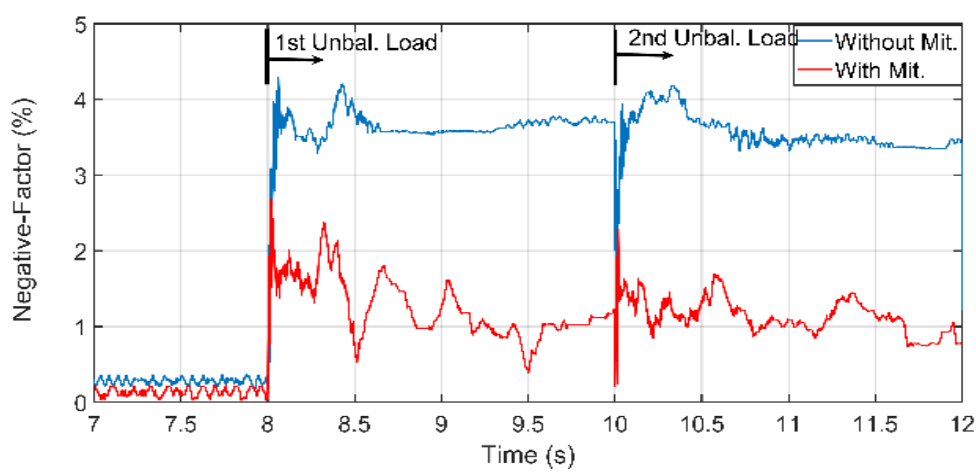

(c)

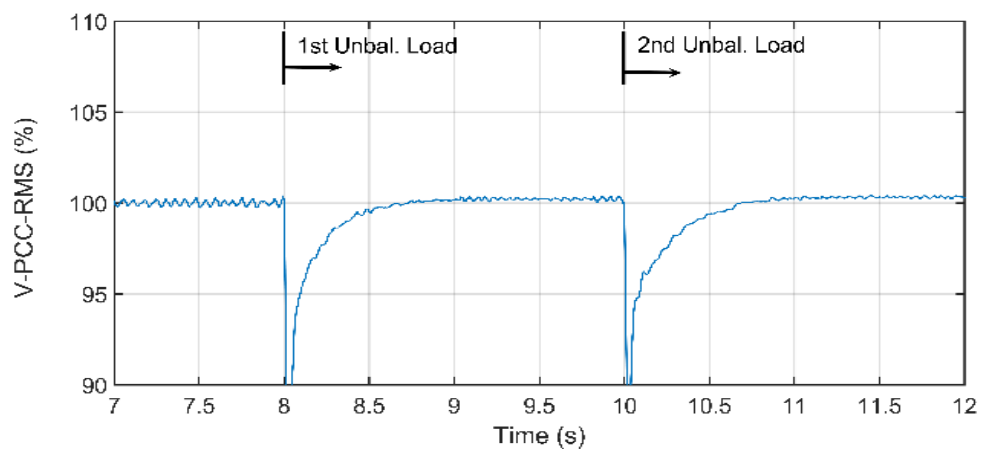

(d)

Figure 6. (c) Negative-sequence factor during different unbalanced loads without and with mitigation, (d) Instantaneous percent RMS voltage at PCC during unbalanced loads (continue)

The performance of mitigating the unbalance is evaluated by measuring the negative-sequence factor. This negative-sequence factor is defined in the IEEE Standard 1159-1995, where its value should be less than $2 \%$. The negative-sequence factor is displayed in Figure 6 (c) before and after activating the control loop. This figure reveals that the proposed scheme/controller efficiently mitigate the negative-sequence voltages. Finally, the instantaneous percent RMS voltage is given in Figure 6 (d).

\subsection{Microgrid in grid-connected operation}

The parameters of the advanced exponential SMC for this mode are listed in Table 6.

Table 6. Settings of proposed controllers for power management

\begin{tabular}{cccc}
\hline \multicolumn{2}{c}{ PARAMETERS OF PROPOSED SMC } & \multicolumn{2}{c}{ MICROGRID POWER FOR LOADS } \\
d- AXIS & q- AXIS & $P_{\text {loads-microgrid }}=P_{\text {ref-floating }}$ \\
\hline$\lambda_{1}=1, \lambda_{2}=225$ & $\lambda_{1}=1, \lambda_{2}=405$ & $P_{\text {ref }}=0.284 p u$ & $Q_{\text {ref }}=0.098 p u$ \\
$k=0.8, \alpha=0.5$ & $k=0.8, \alpha=0.5$ & \\
$\mu=0.75, \rho=0.95, \delta_{0}=0.36$ & $\mu=0.75, \rho=0.95, \delta_{0}=0.35$ & \\
\hline
\end{tabular}

This power management control is responsible for setting the power (active and reactive) exchanged between both grids, but it has nothing to do with voltage and frequency control. In this research, the suggested procedure for a seamless transition from the islanded mode to the grid-connected mode is summarized as,

a. Adjust the power reference $\left(P_{\text {ref-floating }}, Q_{\text {ref-floating }}\right)$ such that it becomes equal to the total power taken by the only loads in the microgrid while the microgrid is still in an autonomous mode (microgrid is not connected to the main grid yet).

b. After the $1^{\text {st }}$ step is realized, the tie-feeder breaker is closed, the control scheme automatically shifts the operation from the microgrid mode to the grid-connected mode (power management control loop) as shown in Figure 2. Both microgrid and power grid are in the floating mode, where there is no exchanged power in the tie-feeder. Thus, the current in the tie feeder is zero at this floating mode.

c. After the step 2 is realized, power references are set to any value to let more power go in the tie-feeder and to exchange power between the microgrid and power grid. 
The performance of the power management control is depicted in Figure 7. In Figure 7 (a) for time $\mathrm{t}<18 \mathrm{~s}$, the microgrid is still operated at an autonomous mode and power references are adjusted to $P_{\text {ref }}=0.284 \mathrm{pu}$ and $Q_{r e f}=0.098 \mathrm{pu}$, which are the same power taken by local loads of microgrid $\left(P_{\text {ref-floating }}, Q_{\text {ref-floating }}\right)$. At time $\mathrm{t}=18 \mathrm{~s}$, the tie feeder switch is closed, then the operation is automatically transferred from the primary (current) and secondary (voltage) control loops (microgrid mode) to the power management control loop (grid-connected mode) as shown in Figure 2. At time $\mathrm{t}=18 \mathrm{~s}$, there is a slight disturbance, which ends within $1 \mathrm{~s}$. At this floating condition, the power in the tie feeder $P_{\text {tie }}$ is zero and no exchanged power between both grids and the current in the tie feeder is zero $\left(I_{\text {tie }}=0 A-\right.$ floating condition $)$. At time $\mathrm{t}=21 \mathrm{~s}$, the active power reference is just to $80 \%$ of the power taken by local loads $\left(P_{r e f}=0.227 \mathrm{pu}\right)$. Thus, for the time from $21 \mathrm{~s}$ to $24 \mathrm{~s}$, the microgrid $(\mathrm{MG})$ imports active power from the power grid, which is equivalent to the tie power with a negative sign, $\left(P_{\text {tie }}\right.$ is negative $)$. After time $\mathrm{t}>24 \mathrm{~s}$, the power reference is set to $150 \%$ of the power taken by local loads $\left(P_{\text {ref }}=0.426 \mathrm{pu}\right)$, then the injected power tracks the reference and the microgrid injects the surplus to the power grid, which is equivalent to the active power of tie feeder $\left(P_{t i e}\right)$ with a positive sign. In Figure 7 (a), the injected power of the inverters $\left(P_{P C C}\right)$ meticulously follows the power reference $\left(P_{r e f}\right)$ with the minimum chattering and settling time of $1 \mathrm{~s}$. The reactive power performance of Figure 7 (b) has the similar sequence as explained for the active power of Figure 7 (a).

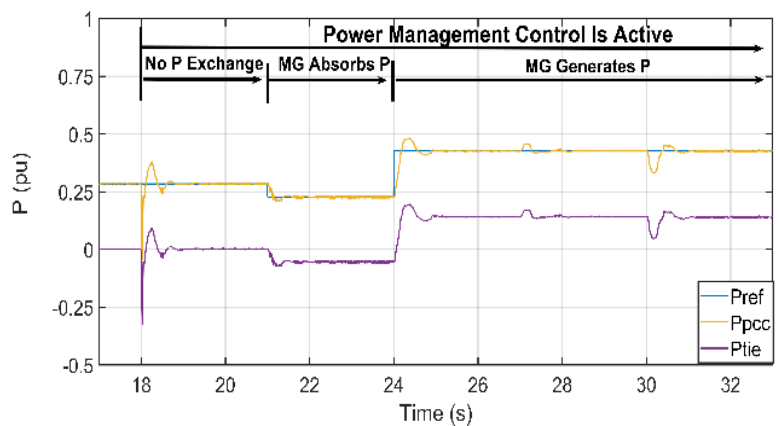

(a)

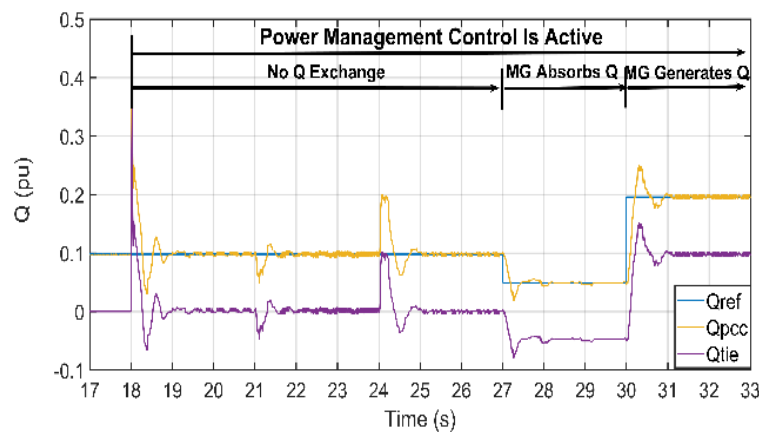

(b)

Figure 7. (a) Active power exchanged between microgrid and main power grid, (b) Reactive power exchanged between microgrid and main power grid

\section{CONCLUSION}

This paper develops an efficient controller (advanced power-rate exponential SMC) for the operation of the parallel inverters forming a microgrid. The suggested scheme belongs to the communication-less and centralized control category for the microgrid operation. The proposed control scheme proves to be efficient for the microgrid operation such that the voltage and frequency at the point of common coupling are almost constant at $1 \mathrm{pu}$ with variable balanced and unbalanced loads. The suggested control scheme gives a better performance at the reaching and sliding modes compared to other linear and nonlinear controllers for the same loading conditions. More importantly, the proposed control scheme enables the microgrid to be operated in an autonomous mode and grid-connected mode to seamlessly exchange power with the power grid.

\section{REFERENCES}

[1] IEEE Standard 2030.7-2017, "IEEE Standard for Specifications of Microgrid Controller," [Online]. Available: https://standards.ieee.org/standard/2030_7-2017.html.

[2] Mohd A, Ortjohann E, Morton D, Omari O, "Review of control techniques for inverters parallel operation," Elsevier-Electric Power System Research, vol. 80, no. 12, pp. 1477-1487, Dec 2010.

[3] A. S. Dobakhshari, S. Azizi and A. M. Ranjbar, "Control of microgrids: Aspects and prospects," 2011 International Conference on Networking, Sensing and Control, Delft, pp. 38-43, 2011.

[4] Khadem S.K, Basu M, Conlon M.F, "Parallel operation of inverters and active power filters in distributed generation system- a review," Elsevier, Renewable and Sustainable Energy Reviews, vol. 15, no. 9, pp. 5155-5168, 2011.

[5] S. N. Bhaskara and B. H. Chowdhury, "Microgrids - A review of modeling, control, protection, simulation and future potential," 2012 IEEE Power and Energy Society General Meeting, San Diego, CA, pp. 1-7, 2012.

[6] J. Rocabert, A. Luna, F. Blaabjerg and P. Rodríguez, "Control of Power Converters in AC Microgrids," in IEEE Transactions on Power Electronics, vol. 27, no. 11, pp. 4734-4749, Nov 2012.

[7] D. E. Olivares et al., "Trends in Microgrid Control," in IEEE Transactions on Smart Grid, vol. 5, no. 4, pp. 1905-1919, July 2014. 
[8] Vandoorn T.L, De Kooning J. D. M, Meersman B, Vandevelde L, "Review of primary control strategies for island microgrids with power-electronic interfaces," Elsevier- Renewable and Sustainable Energy Reviews, vol. 19, pp. 613-628, March 2013.

[9] P. Borazjani, N. I. A. Wahab, H. B. Hizam and A. B. C. Soh, “A review on microgrid control techniques," 2014 IEEE Innovative Smart Grid Technologies - Asia (ISGT ASIA), Kuala Lumpur, pp. 749-753. 2014.

[10] M. Yazdanian and A. Mehrizi-Sani, "Distributed Control Techniques in Microgrids," in IEEE Transactions on Smart Grid, vol. 5, no. 6, pp. 2901-2909, Nov 2014.

[11] H. Han, X. Hou, J. Yang, J. Wu, M. Su and J. M. Guerrero, "Review of Power Sharing Control Strategies for Islanding Operation of AC Microgrids," in IEEE Transactions on Smart Grid, vol. 7, no. 1, pp. 200-215, Jan. 2016.

[12] Bouzid A. M, Guerrero J. M, Cheriti A, Bouhamida M, Sicard P, Benghanem M. "A survey on control of electric power distributed generation systems for microgrid applications," Elsevier-Renewable and Sustainable Energy Review, vol. 44, pp. 751-766, April 2015.

[13] Monica P, Kowsalya M, "Control strategies of parallel inverters in renewable energy application: a review," Elsevier-Renewable and Sustainable Energy Reviews, vol. 65, pp. 885-901, Nov 2016.

[14] B. M. Eid, N. A. Rahim, J. Selvaraj and A. H. El Khateb, "Control Methods and Objectives for Electronically Coupled Distributed Energy Resources in Microgrids: A Review," in IEEE Systems Journal, vol. 10, no. 2, pp. 446-458, June 2016.

[15] Hossain M. A, Pota H. R, Issa W, Hoosain M. J, "Overview of AC microgrid controls with inverter-interfaced generations," Journal of Energies, vol. 10, no. 9, pp. 1-27, 2017.

[16] Tayab U. B, Bin-Roslan M. A, Hwai L. J, Kashif M, "A review of droop control techniques for microgrid," Elsevier- Renewable and Sustainable Energy Reviews, vol. 76, pp. 717-727, Sep 2017.

[17] Andishgar M. H, Gholipour E, Hooshmand R. A, "An overview of control approaches of inverter-based microgids in islanding mode of operation," Elsevier- Renewable and Sustainable Energy Reviews, vol. 80, pp. 1043-1060, 2017.

[18] S. M. Kaviri, M. Pahlevani, P. Jain and A. Bakhshai, "A review of AC microgrid control methods," 2017 IEEE 8th International Symposium on Power Electronics for Distributed Generation Systems (PEDG), Florianopolis, pp. 1-8, 2017.

[19] A. Alfergani, K. A. Alfaitori, A. Khalil and N. Buaossa, "Control strategies in AC microgrid: A brief review," 2018 9th International Renewable Energy Congress (IREC), Hammamet, pp. 1-6, 2018.

[20] D. Sera et al., "Low-cost digital implementation of proportional-resonant current controllers for PV inverter applications using delta operator," 31st Annual Conference of IEEE Industrial Electronics Society, IECON 2005, Raleigh, NC, pp. 6, 2005.

[21] Teodorescu R, Blaabjerg F, Liserre M, Loh P.C, "Proportional-resonant controllers and filters for grid-connected voltage-source converters," IEE Proc. of Electric Power Applications, vol. 153, no. 5, pp. 750-762, Sep 2006.

[22] E. A. A. Coelho, B. R. Menezes, P. C. Cortizo and P. F. Donoso Garcia, "Sliding mode controller for parallel connected inverters," 6th IEEE Power Electronics Congress. Technical Proceedings. CIEP 98 (Cat. No.98TH8375), Morelia, Mexico, pp. 96-102, 1998.

[23] Sofia M. A, Gharehpetian G. B, "Dynamic performance enhancement of microgrids by advanced sliding mode controller," Elsevier- Journal of Electric Power and Energy Systems, vol. 33, no1, pp. 1-7, Jan 2011.

[24] YaDong Liu, Yan Xing, Lipei Huang and M. Sakane, "Progressively converging deadbeat control for UPS inverter," Twenty-First Annual IEEE Applied Power Electronics Conference and Exposition, APEC '06, Dallas, TX, pp. 7, 2006.

[25] M. Wang, F. Li, Y. Liu, L. Huang and M. Sakane, "Distributed Parallel Operation of Modified Deadbeat Controlled UPS Inverters," 2007 IEEE Power Electronics Specialists Conference, Orlando, FL, pp. 1727-1732, 2007.

[26] T. Wu, Y. Wu, H. Hsieh and Y. Chen, "Current Weighting Distribution Control Strategy for Multi-Inverter Systems to Achieve Current Sharing," in IEEE Transactions on Power Electronics, vol. 22, no. 1, pp. 160-168, 2007.

[27] Y. Chen and K. Smedley, "Parallel operation of one-cycle controlled grid connected three-phase inverters," Fourtieth IAS Annual Meeting, Conference Record of the 2005 Industry Applications Conference, 2005, Kowloon, Hong Kong , pp. 591-598, 2005

[28] P. H. Divshali, A. Alimardani, S. H. Hosseinian and M. Abedi, "Decentralized Cooperative Control Strategy of Microsources for Stabilizing Autonomous VSC-Based Microgrids," in IEEE Transactions on Power Systems, vol. 27, no. 4, pp. 1949-1959, Nov 2012.

[29] M. Borrega, L. Marroyo, R. González, J. Balda and J. L. Agorreta, "Modeling and Control of a Master-Slave PV Inverter With N-Paralleled Inverters and Three-Phase Three-Limb Inductors," in IEEE Transactions on Power Electronics, vol. 28, no. 6, pp. 2842-2855, June 2013.

[30] Tsai-Fu Wu, Yu-Kai Chen and Yong-Heh Huang, "3C strategy for inverters in parallel operation achieving an equal current distribution," in IEEE Transactions on Industrial Electronics, vol. 47, no. 2, pp. 273-281, April 2000.

[31] Elnady A, Suleiman M. S, "Simulation and experimental comparison between multilevel and conventional inverters," Journal of Power and Energy Systems, ACTA Press, vol. 9, pp. 482-492, 2017.

[32] C. J. Fallaha, M. Saad, H. Y. Kanaan and K. Al-Haddad, "Sliding-Mode Robot Control With Exponential Reaching Law," in IEEE Transactions on Industrial Electronics, vol. 58, no. 2, pp. 600-610, Feb 2011.

[33] S. M. Mozayan, M. Saad, H. Vahedi, H. Fortin-Blanchette and M. Soltani, "Sliding Mode Control of PMSG Wind Turbine Based on Enhanced Exponential Reaching Law," in IEEE Transactions on Industrial Electronics, vol. 63, no. 10 , pp. 6148-6159, Oct 2016 .

[34] K. B. Devika and S. Thomas, "Improved sliding mode controller performance through power rate exponential reaching law," 2017 Second International Conference on Electrical, Computer and Communication Technologies (ICECCT), Coimbatore, pp. 1-7, 2017. 